\title{
Administração de Medicamentos por Via Parenteral: Uma Revisão
}

\section{Drug administration for parenteral route: A review}

\section{Marcos Luciano Pimenta Pinheiro ${ }^{1}$, Ronilson Ferreira Freitas ${ }^{1}$, Denise Pinho Resille ${ }^{1}$, Thamara de Souza Campos ${ }^{1}$}

${ }^{1}$ Universidade Federal dos Vales do Jequitinhonha e Mucuri - UFVJM, Diamantina, Minas Gerais, Brasil.

\section{Resumo}

Introdução: A administração de medicamentos é uma das atividades mais sérias e de maior responsabilidade da Enfermagem. Para sua execução, exige-se competência, conhecimentos, habilidades e aplicação de princípios científicos no que diz respeito ao preparo, às vias de administração e aos eventos adversos. Objetivo: Esse artigo teve como objetivo realizar uma revisão bibliográfica sobre a administração de medicamentos por via parenteral direta, no que diz respeito ao local de aplicação, material utilizado e à técnica descrita na literatura. Metodologia: A metodologia utilizada foi a busca e leitura exploratória, seletiva, analítica e interpretativa de artigos publicados em periódicos científicos considerando as vias de administração intradérmica, subcutânea, intramuscular e intravenosa; local de aplicação, material utilizado e técnica. Através desse estudo, é possível ressaltar a importância da difusão de conhecimentos por meio da educação continuada dos profissionais responsáveis pela administração de medicamentos.

Palavras-chave: Vias de administração de medicamentos; Enfermagem; Sistemas de medicação.

Autor correspondente:

Marcos Luciano Pimenta Pinheiro

E-mail: marcospimenta2@ufvjm.edu.br
Recebido em: 18/08/2015 Revisado em: 01/05/2016

Aceito em: 06/05/2016

Publicado em: 15/06/2016 


\section{Abstract}

Introduction: Medication administration is one of the most serious activities and of greater responsibility of Nursing. In order to implement it, one should require competence, knowledge, abilities and application of scientific principles as regards the preparation, the administration routes and the adverse events. Objective: This papper was aimed at performing a bibliographic review about medication administration by means of direct parenteral route, as regards the application area, the material to be used and the technique described in the literature. Methodology: The methodology used was the exploratory, selective, analytical and interpretive search and regarding o peppers published in scientific journals by considering the intradermal, subcutaneous, intramuscular and intravenous administration routes; application area, material to be used and technique. Through this study, one can highlight the importance of spreading knowledge by means of continuous education of through professionals responsible for medication administation.

Keywords: Medication administration routes; Nursing; Medication systems.

\section{Introdução}

O processo de medicar inclui etapas interrelacionadas e diretamente interligadas por uma equipe multiprofissional, percorrendo um caminho que se inicia na prescrição médica, continua com a provisão pelo farmacêutico e termina com o preparo e administração pela equipe de enfermagem ${ }^{\mathbf{1}}$.

A administração de medicamentos por via parenteral é considerado um procedimento simples, entretanto, por ser um processo invasivo requer certos cuidados, exigindo maior responsabilidade dos profissionais da enfermagem ${ }^{2}$. Para sua execução exige-se competência, conhecimentos, habilidades e aplicação de princípios científicos no que diz respeito ao preparo, às vias de administração e aos eventos $\operatorname{adversos}^{3,4}$.

Assim, o exercício dessa atividade é estabelecido pela Lei $\mathrm{n}^{\mathbf{0}} 7.498$, de 08 de junho de 1987, que regulamenta o exercício profissional de enfermagem e a responsabiliza pela prática da administração de medicamentos ${ }^{5}$, fazendo com que o processo de administação de medicamentos pelo enfermeiro seja mais que um simples procedimento técnico, pois há uma interação complexa envolvendo o enfermeiro e o indivíduo a ser cuidado. Essa interação imbui à experiência de vida, a ética moral e profissional do enfermeiro, respeitando-se os direitos legais, culturais e os valores do indivíduo assistido ${ }^{6}$.

Preconizam-se atualmente os "nove certos" centrados no paciente: medicação, via, dose, hora, registro, conhecer a ação, apresentação farmacêutica e monitorar o efeito. Sabe-se que é o medicamento certo conferindo a prescrição, o rótulo e administrando somente o que foi preparado pessoalmente ${ }^{7}$.
A dose certa é assegurada pela medida exata, o cálculo correto e a fragmentação uniforme do medicamento. Para determinar o cliente certo é necessário o reconhecimento do paciente, perguntando-lhe o nome e conferindo a placa de identificação. Quanto à via certa, a prescrição médica deve conter a via de administração de cada medicamento e, se não estiver explícita, o enfermeiro deve comunicar ao médico; é importante ressaltar que o preparo do medicamento deve ser condizente com a via de administração. A hora certa precisa ser pontual, não havendo atrasos ou antecipações; além disso, é preciso estar atento às condições do paciente e adaptar os horários as suas condições clínicas ${ }^{1}$.

A via de administração tem grande importância na relação efeito da droga/benefício para o paciente. O percurso realizado pelas moléculas da droga dentro do organismo envolve sua absorção, distribuição, metabolismo e eliminação ${ }^{4}$, daí a importância da assistência de um profissional habilitado para a administração dos medicamentos. Para uma boa assistência, um ambiente seguro para administração envolve recursos físicos (luminosidade, controle da temperatura, silêncio) e humanos (profissionais suficientes, capacitados e com experiência) ${ }^{8}$.

Sendo assim, os profissionais envolvidos no sistema de medicação devem ter conhecimento de farmacologia, no que se refere ao mecanismo de ação, farmacocinética, efeitos colaterais, reações adversas e interações medicamentosas dos fármacos ${ }^{9}$, além de dominarem os métodos, vias, locais, ações, dose, diluições, técnicas, assepsia e utilização de materiais estéreis ${ }^{10}$.

Muitos estudos demonstram que os erros de administração de medicamentos produzem efeitos deletérios, prejuízos/danos, lesões aos pacientes ${ }^{5}$. É 
importante notar que a falta de atenção, falta de conhecimento e informação sobre os medicamentos são fatores de risco para a ocorrência de $\operatorname{erros}^{3}$. Com isso, releva-se a importância da ação educativa contínua aos profissionais envolvidos diretamente na prática de administração de medicamentos, promovendo a qualidade do cuidado ao paciente ${ }^{11}$.

Observando a necessidade de atualização dos profissionais de Enfermagem e a carência de estudos que versam sobre a administração de medicamentos por via parenteral direta, o presente artigo tem como objetivo realizar uma revisão bibliográfica sobre esta temática, no que diz respeito ao local de aplicação, material utilizado e à técnica descrita na literatura.

\section{Metodologia}

Para atingir os objetivos propostos neste trabalho, foi realizada uma pesquisa com procedimentos bibliográficos, exploratória de natureza qualitativa. De acordo com Rampazzo ${ }^{12}$, a pesquisa bibliográfica procura explicar um problema a partir de materiais já elaborados, constituídos principalmente de livros e artigos científicos, a fim de proporcionar melhor visão do problema e torná-lo mais específico, possibilitando a construção de hipóteses e assumindo um caráter de estudo exploratório, visando conhecer os fatos e fenômenos relacionados ao tema. Para Minayo ${ }^{13}$ a pesquisa qualitativa trabalha com o universo de significados, motivos, aspirações, preocupa-se com aspectos que não podem ser quantificados, centrando-se na compreensão e nas explicações da dinâmica das relações sociais, sendo o pesquisador considerado um instrumento de coleta de dados, responsável por interpretar os dados de forma indutiva.

Para auxílio no desenvolvimento do presente estudo, foram utilizados como fonte de dados, artigos científicos originais e de revisão disponíveis nas bases de dados da Biblioteca Virtual da Saúde (Bireme), Scientific Electronic Library Online (Scielo) e Google Acadêmico publicados no período de 1997 a 2015, além de livros na área da saúde referentes ao tema proposto. A seleção dos artigos foi definida pelo seguinte modelo: artigos em português, inglês e espanhol, que discutiam sobre a administração de medicamentos por via parenteral direta, no que diz respeito ao local de aplicação, material utilizado e à técnica descrita na literatura. Os descritores utilizados foram: vias de administração de medicamentos, enfermagem e sistemas de medicação, e seus respectivos termos em inglês e espanhol.

Após a indicação das referências, passou-se ao processo de leitura com as seguintes etapas: 1) Leitura exploratória, para verificar a adequação das referências ao interesse da pesquisa; 2) Leitura seletiva, determinando, de fato, o material de interesse à pesquisa; 3) Leitura analítica, ordenando e sumarizando as informações; 4) Leitura interpretativa em que se chega a significados mais amplos.

\section{Discussão}

Dentre as diferentes formas de administrar um medicamento, a via de administração parenteral constitui uma das mais empregadas na veiculação de fármacos e vacinas. Essa via permite a liberação da substância farmacologicamente ativa em regiões próximas à corrente sanguínea ou diretamente nela, possibilitando efeito rápido e ação que pode ser sistêmica ou localizada, dependendo do local de aplicação. Contudo, a perfuração da pele com agulhas necessária para acessar o local pretendido, além de incômodo ao paciente, eleva o risco de infecções e de reações locais ${ }^{14}$.

De acordo com a Organização Mundial da Saúde (OMS), em 2008, o uso incorreto de injeções provocou infecção em 340 mil indivíduos pelo vírus da Imunodeficiência Humana (HIV), quinze milhões foram contaminados com hepatite B, cerca de um milhão contraíram hepatite $\mathrm{C}$ e mais três milhões apresentaram infecções bacterianas diversas ${ }^{15}$. Esses dados evidenciam a razão pela qual é mandatória a administração de injeções por pessoal especializado e em condições de assepsia ${ }^{14}$.

O preparo e a administração de medicamentos é uma das atribuições da enfermagem, sendo o seu desempenho de grande relevância, por tratar-se de uma das maiores responsabilidades da equipe no que se refere aos cuidados prestados ao paciente. Atualmente, a administração incorreta de medicamentos constitui um grave problema nos serviços de saúde, sendo considerado um dos principais efeitos adversos sofridos por pacientes hospitalizados ${ }^{16}$.

Para que haja segurança no desenvolvimento dessa atividade, faz-se necessário que os profissionais envolvidos no sistema de medicação tenham o conhecimento técnico e científico das patologias, farmacologia, anatomia e fisiologia e o entendimento dos eventos adversos que possam surgir no processo de preparo e administração de medicamentos, fase na qual a literatura tem relatado a ocorrência de erros ${ }^{17}$ , 18

Estudo realizado por Lemos et $\mathrm{al}^{18}$ relatou grande incidência de falhas relacionadas a técnicas básicas durante o preparo e administração de medicamentos. Foram observadas falhas na lavagem das mãos antes do início do preparo das medicações, ausência de assepsia de ampolas e do procedimento de lavagem de sondas nasogástricas e nasoentéricas antes ou depois da administração de medicamentos. A literatura considera essas situações como de consequiência insignificante, entretanto esses são procedimentos básicos que devem ser respeitados, sendo que o último, mesmo sendo um fator que não leva ao erro, é considerado falha no processo medicamentoso ${ }^{18}$.

Assim, antes de qualquer procedimento, a higienização das mãos é de extrema importância, além de ser um gesto simples, previne a ocorrência de 
infecções hospitalares ${ }^{19}$. O preparo da medicação deve ser feito de forma asséptica, cabendo à equipe de Enfermagem a escolha da seringa e agulha compatíveis à técnica, medicamento e cliente. Cada seringa/agulha é destinada a administrar determinado volume de medicamento para um tipo especifico de tecido descrito a seguir ${ }^{19}$. A aspiração é também parte importante do preparo. Os medicamentos poderão estar acondicionados em ampolas ou frascos; em ambos, é necessária a desinfecção do recipiente para evitar a contaminação da solução ${ }^{20}$.

A escolha do local deve considerar a distância em relação a vasos e nervos, a capacidade da musculatura, a espessura do tecido adiposo, a idade e irritabilidade do paciente ${ }^{21}$. Além disso, a pele deve estar íntegra, sem a presença de lesões ou edemaciada $\mathrm{e}$, antes da aplicação, deve-se realizar a anti-sepsia ${ }^{22}$.

Para cada uma das vias há um local específico, utilizado para determinadas substâncias e indicações, como também uma forma de aplicação e demais peculiaridades descritas na literatura.

A via intradérmica é indicada para testes de hipersensibilidade. As áreas corpóreas ideais são aquelas sem pelos e pouco pigmentadas. Os locais são, principalmente a face interna do antebraço e a parte superior das costas. O ângulo de inserção deve ser de 5 a $15^{\circ}$ com o bisel voltado para cima, deverá ser utilizada seringa de $1 \mathrm{~mL}$ e agulha de $13 \times 4 \mathrm{~mm}$ ou $13 \times 3,8 \mathrm{~mm}$, sendo o volume máximo a ser administrado de 0,1 a $1 \mathrm{~mL}$. A formação de uma bolha no local da injeção é um indicativo de que a técnica está correta $^{19}$. A administração não é recomendada se a pele do paciente estiver úmida, outra recomendação é a inserção apenas do bisel da agulha e sua retirada no mesmo ângulo da inserção. $\mathrm{O}$ local não deve ser massageado ${ }^{20}$.

A via subcutânea é indicada principalmente para medicamentos de absorção lenta, entre os mais conhecidos estão a heparina, a insulina e as vacinas. Os sítios indicados para essa técnica são a face posterior externa dos braços, o abdome, face anterior da coxa, áreas escapular, glútea ventral superior e dorsal. O ângulo de inserção é de 45 a $90^{\circ}$ dependendo da agulha e do tecido adiposo do paciente. A seringa recomendada para essa técnica é de 1 ou $3 \mathrm{~mL}$, a agulha utilizada é a $13 \times 4,5 \mathrm{~mm}$ ou $13 \times 3,8 \mathrm{~mm}$, e o volume máximo administrado deve ser de 1 a $3 \mathrm{~mL}$. É preciso ressaltar que não são aconselháveis aplicações repetidas no mesmo local, aspirar injeções de heparina, nem massagear o local quando administrado insulina ou heparina ${ }^{23}$.

A via intramuscular é indicada para medicamentos que necessitem absorção mais rápida, e também medicamentos mais viscosos e irritantes porque os músculos são menos sensíveis a essas substâncias. O ângulo de inserção é de $90^{\circ}$, entretanto, dependendo da massa muscular do indivíduo pode ser feita em ângulo menor. A seringa a ser utilizada depende do músculo onde será administrado o medicamento, sendo a agulha de $25 \times 7$ $\mathrm{mm}$ ou $25 \times 8 \mathrm{~mm}^{19}$.

Quanto aos locais de aplicação podem-se utilizar quatro músculos, citados em ordem dos mais indicados por questões de assepsia, distância de inervações e capacidade muscular para soluções:

Ventro glúteo - envolve os músculos glúteo médio e mínimo. Para localizar, coloca-se a palma da mão sobre região do trocânter maior do quadril do paciente, usando a mão oposta ao lado da aplicação. $\mathrm{O}$ polegar aponta para virilha, o indicador para a espinha ilíaca ântero-superior e estende-se o dedo médio para trás, formando um triângulo em V. Este é o sítio da injeção. Para esse músculo, deve ser utilizadas seringas de $5 \mathrm{~mL}$, e o volume máximo administrado em crianças é de $2 \mathrm{~mL}$ e $4 \mathrm{~mL}$ em $\operatorname{adultos}^{19,20}$.

Vasto Lateral - o músculo localiza-se na face ântero-lateral da coxa e estende-se, em um adulto, aproximadamente desde $10 \mathrm{~cm}$ acima do joelho até 5 $\mathrm{cm}$ abaixo do trocânter maior do fêmur. $\mathrm{O}$ terço médio é o local de aplicação ${ }^{19}$.

Dorso glúteo - O músculo glúteo máximo é local tradicional para injeções, mas por existir um risco de atingir o nervo isquiático não é recomendado em algumas ${ }^{1}$. Para delimitar o local de aplicação fazse uma linha imaginária desde a espinha ilíaca póstero-superior até o grande trocânter do fêmur; a injeção é realizada no quadrante superior externo ${ }^{24}$.

Deltóide - O músculo não é bem desenvolvido, sendo utilizado para administração de pequenos volumes. Colocam-se quatro dedos da mão não dominante apoiados ao músculo, atentando para que o dedo superior encontre-se no processo acromial. O sítio da injeção fica três dedos abaixo do processo acromial $^{19}$, ou seja, ao limite inferior traçado pelos dedos.

Há muitas vantagens na escolha da via intravenosa, no que se refere à rapidez de resposta ao medicamento. Provoca menos desconforto ao paciente quando comparada a outras vias, se os medicamentos são alcalinos ou irritantes. A aplicação pode ser feita em sítio de acesso intravenoso já existente, isso depende da política da instituição ${ }^{19}$.

A administração intravenosa pode ser feita de forma lenta e contínua, em bolo e em infusão juntamente com outra solução. Pode ser realizada em vários locais com acesso periférico ou central. A escolha exige o acompanhamento atento do paciente durante a administração medicamentosa ${ }^{24}$.

A função principal da Enfermagem é o cuidado do paciente. Tratando-se de administração de medicamentos, além de segurança na aplicação, o conhecimento das condições clínicas do paciente e acompanhamento é indispensável. Durante e após a administração deve-se notar os efeitos que a droga provoca. Assim, é observada uma preocupação 
mobilizada por parte dos profissionais de saúde em geral, já que a questão da segurança, das práticas seguras e da biossegurança é uma demanda atualizada, principalmente no que se refere ao preparo e administração de medicamentos.

\section{Conclusão}

Esta revisão permitiu conhecer estudos que exploraram esta temática no período compreendido e as abordagens utilizadas.

A administração de medicamentos por via parenteral traz em si peculiaridades definidas na literatura que devem ser exploradas cada vez mais para proporcionar uma atualização dos conhecimentos a todos os profissionais que tem a responsabilidade na aplicação de fármacos.

Neste sentido, ressalta-se a importância da educação continuada como difusão do conhecimento, o que produz a maior efetividade dos procedimentos de administração de medicamentos como também a minimização dos erros.

\section{Declaração de conflitos de interesses}

Os autores declaram não haver conflito de interesses.

\section{Referências}

1. MIASSO, A. I.; CASSINI, S. H. B. Erros na administração de medicamentos: divulgação de conhecimentos e identificação do paciente como aspectos relevantes. Rev. Esc. Enferm. USP. v. 34, n. 1, p. 16-25, 2000 .

2. FREITAG, V. L.; DALMOLIN, I. S.; BADKE, M. R.; PETRONI, S. Injeções intramusculares ventroglútea: o conhecimento da técnica pelos profissionais de enfermagem. Rev. Enferm. UFPE on line., Recife. v. 9, n. 2, p. 799-805, 2015.

3. CARVALHO, V. T.; CASSIANI, S. H. B.; CHIERICATO, C. Erros mais comuns e fatores de risco na administração de medicamentos em unidades básicas de saúde. Rev. Latino-Am. Enfermagem. v. 7, n. 5, p. 67-75, 1999.

4. OLIVEIRA, M. R.; GASTALDI, A. B. Hipervolemia e flebite relacionadas à administração de medicamentos. Terra e Cultura. n. 39, p. 155-62, 2004.

5. SCHNEIDER, D. G.; RAMOS, F. R. S. Processos éticos de enfermagem no Estado de Santa Catarina: caracterização de elementos fáticos. Rev. Latino-Am. Enfermagem. v. 20, n. 4, 2012.

6. OLIVEIRA, M. C. P.; KANASHIRO, C. A. A responsabilidade da equipe de enfermagem na administração medicamentosa. Olhares Plurais. v. 2, n. 3, p. 43-49, 2010.
7. SILVA, L. D.; CAMERINI, F. G. Análise da administração de medicamentos intravenosos em hospital da rede sentinela. Texto Contexto Enferm, Florianópolis. v. 21, n. 3, p. 633-41, 2012.

8. CARVAlHO, V. T.; CASSIANI, S. H. B. Erros na medicação e consequiências para profissionais de enfermagem e clientes: um estudo exploratório. Rev. Latino-Am Enfermagem. v. 10, n. 4, p. 523-9, 2002.

9. OLIVEIRA, R. C., MIASSO, A. I.; CASSIANI, S. H. B. Setor de Emergência: Situações de erros na medicação. In: TELLES FILHO, P. C. P, STUCHI RAG, organizadores: A Enfermagem no novo milênio: Uma abordagem multidisciplinar. Belo Horizonte: Difusora. 96106, 2008.

10. TElles Filho, P. C. P.; CASSIANI, S. H. B. Administração de medicamentos: aquisição de conhecimentos e habilidades requeridas por um grupo de enfermeiros. Rev. Latino-Am. Enfermagem. v. 12, n. 3, p. 533-40, 2004.

11. PRAXEDES, M. F; S.; TElles FIlHO, P. C. P. Identificação de erros no preparo e administração de medicamentos pela equipe de enfermagem e das ações praticadas pela instituição hospitalar. Cogitare Enferm. v. 13, n. 4, p.520-5, 2008.

12. RAMPAZZO, L. Metodologia cientifica: para alunos de graduação e pós-graduação. Rev. de Maurício Balthazar Leal e Rita de Cássia Machado Lopes. 3. ed. São Paulo: Loyola, 2005.

13. MINAYO, M. C. S. O desafio do conhecimento. Pesquisa qualitativa em saúde. Rio de Janeiro: Hucitec;ABRASCO, 2001.

14. BORGHETI-CARDOSO, L. N.; CUNHA-FILHO, M.; GELFUSO, G. M.; GRATIERI, T. Injeção sem agulhas: aplicações médicas e perspectivas futuras. Brasília Med. v. 50, n. 3, p. 253-260, 2013.

15. WORLD HEALTH ORGANIZATION (WHO). Annual Meeting of the Safe Injection Global Network. Dubai, United Arab Emirates; 2010.

16. GALIZA, D. D. F.; MOURA, O. F.; BARROS, V. L.; LUZ, G. O. Preparo e administração de medicamentos: erros cometidos pela equipe de enfermagem. Rev. Bras. Farm. Hosp. Serv. Saúde. São Paulo, v.5, n.2, p. 45-50, 2014.

17. LUEDY, A.; SOUSA, A. R.; SACRAMENTO, B. I. L; MURICY, S. M. Estratégias para prevenir erros na administração de medicações de alta vigilância. Revista Acreditação. v.1, n.2, p. 93-110, 2011.

18. LEMOS, N. R. F.; SILVA, V. R.; MARTINEZ, M. R. Fatores que predispõem à distração da equipe de enfermagem durante o preparo e a administração de medicamentos. Rev. Min. Enferm. v.16, n. 2, p. 201-207, 2012.

19. POTTER, P. A.; PERRY, A. G. Integridade cutânea e cuidado com feridas. Fundamentos de enfermagem, 2004.

20. CASSIANI, S. H. B. Administração de medicamentos. São Paulo: EPU. p.131, 2000. 
21. OLIVEIRA, V. T.; CASSIANI, S. H. B. O Processo de comunicação na administração de medicações injetáveis em crianças sob a perspectiva da interação entre mãe-criança e auxiliares de enfermagem. Rev. Latino-Am. Enfermagem. v. 5, n. 4, p. 61-7, 1997.

22. RANGEL, S. M.; CASSIANI, S.H. B. Administração de medicamentos injetáveis por via intramuscular: conhecimento dos ocupacionais de farmácias. Rev Esc Enf USP. v. 34, n. 2, p. 138-44, 2000.

23. REICHEMBACH, M. T.; MEIER, M. J.; ASCHIDAMINI, I. M. Administração de medicamentos por via subcutânea: convenção ou controvérsia para a enfermagem? Rev Bras Enferm. v. 58, n. 5, p. 602-6, 2005.

24. CABRAL, I. E. Administração de medicamentos. Rio de Janeiro: Reichmann \& Affonso Editores, 456 p, 2002. 